\title{
Doctoral Advisor-Advisee Pairing in STEM Fields: Selection Criteria and Impact of Faculty, Student and Departmental Factors
}

\author{
Simy Joy \\ University of East Anglia, \\ Norwich, Norfolk, UK \\ simy.joy@uea.ac.uk
}

\author{
Xiangfen Liang \\ Seattle, USA
}

xiangfen.liang@gmail.com

\section{Diana Bilimoria and Susan Perry Case Western Reserve University, Cleveland, Ohio, USA}

\author{
diana.bilimoria@case.edu susan.perry@case.edu
}

\begin{abstract}
Unlike the doctoral programs in places where students are paired with advisors at the time of admission itself, most US programs require the students to choose their advisors, and the advisors to formally accept the students as advisees. Little research has been done to understand how students and faculty approach this mutual selection and pairing process. This paper examines this process in STEM departments (Science, Technology, Engineering and Mathematics), with specific focus on factors influencing the decisions. Based on focus groups and interviews of doctoral students and faculty from STEM departments in an American university, we identify criteria applied by students and faculty in making their choices. Students were found to assess faculty on available funding, area of research, personality, ability to graduate students fast, and career prospects for students, and faculty to assess students on their qualifications/credentials and perceived ability to contribute to research. We also found that this mutual assessment was not objective, but influenced by perceptions associated with faculty gender and career stage, and student nationality. In the end, whether students and faculty were actually paired with persons of their choice depended on departmental factors including prevalent pairing practices, restrictions on student numbers per faculty, and reward structure. We discuss implications of the findings for research and practice.
\end{abstract}

Keywords: Doctoral education, advisor/advisee selection, gender, nationality, career stage

Material published as part of this publication, either on-line or in print, is copyrighted by the Informing Science Institute. Permission to make digital or paper copy of part or all of these works for personal or classroom use is granted without fee provided that the copies are not made or distributed for profit or commercial advantage AND that copies 1) bear this notice in full and 2) give the full citation on the first page. It is permissible to abstract these works so long as credit is given. To copy in all other cases or to republish or to post on a server or to redistribute to lists requires specific permission and payment of a fee. Contact Publisher@InformingScience.org to request redistribution permission.

\section{Introduction}

Advisor-advisee relationship is core to the doctoral education in America as elsewhere. It is through this relation that students are socialized into "the academic field, university setting, research, ethics, and many other important aspects related to being an academic professional" (Wrench \& Punyanunt, 2004, p.225). 
Having the right advisor leads to greater student satisfaction and faster degree completion (de Valero, 2001). Having a wrong one is a key reason for student attrition (Herzig, 2002; Lovitts, 2001), which is estimated to be quite high at 40-50\%, (Golde, 2005). Advisors benefit from this relation when advisees contribute to their research, sometimes leading to long-term collaborative relationships (Wang et al., 2010) and lessen workload by taking on teaching and grading (Offstein, Larson, McNeill \& Mwale, 2004). Incompatible advisees drain faculty resources (Knox, Schlosser, Pruitt \& Hill, 2006).

Jones (2013) reports that 15\% of journal articles published from 1971 to 2012 on doctoral issues focus on advisor-advisee relations. Much of the empirical literature however dwells on issues after advisor/advisee selection has been done, such as factors affecting the success of the relationship (e.g. Schlosser \& Kahn, 2007; Zhao, Golde \& McKormick, 2007) and outcomes (e.g. Herzig, 2002); little is known about how the advisor/advisee selection is done in the first place. Unlike some other places where the students are assigned to advisors when they are admitted to the program, most US doctoral programs require the students to choose their advisors at some point, and the advisors to formally accept the students as advisees. Except for Zhao et al. (2007) (and Ray, 2007 in the Indian context), we have not come across any study that looks at how advisor selection is done. We argue that advisor-advisee selection and pairing warrants more researcher attention, not only because ensuring the advisor-advisee pair is the right match in the beginning itself may contribute to its eventual success, but also because, once made, it is a decision difficult to reverse. Golde (2005) has found that choosing and switching advisors are processes of public and political nature, and as a result, students find it easier to move to another university than to switch advisors. This paper aims to contribute to the scant literature on this topic by bringing to light the dynamics involved in the advisor-advisee pair formation in the US context and the factors affecting the process.

\section{Literature Review}

\section{Advisor-Advisee Selection and Pairing}

Compared to the UK and Europe, doctoral education in the US is highly decentralized and unregulated (Zhao et al., 2007). Unlike the doctoral programs in the UK, Australia, and some of the European countries where the student is paired with an advisor/supervisor by the department at the time of admission, advisor-advisee pairing in the US usually involves the student identifying the faculty that they are interested in working with at some or other stage in the program, and the faculty either accepting or rejecting the student (Golde, 2005; Zhao et al., 2007). The specific practices followed in different academic disciplines, institutions and departments however vary (de Valero, 2001). There is little research that sheds light on how the students and faculty make their advisor/advisee choices.

Choosing an advisor is often thought as the most significant decision that a doctoral student has to take (Ray, 2007). Zhao et al. (2007) suggest that students make their decision based on several criteria. Their factor analysis revealed three major criteria: advisor reputation (as a good teacher, researcher, and advisor), intellectual compatibility (match of the "advisor's intellectual interests and methodological expertise with the student's interests, expectations of ensuring high-quality work"), and pragmatic benefits ("financial support, a favorable work environment") (p.267). Ray (2007) has found that Indian doctoral students apply similar criteria. Zhao et al. (2007) also discovered individual and disciplinary differences in the relative importance attached to each criterion. In the absence of further empirical studies on the topic, we assume that students may seek advisors possessing characteristics that are generally valued, including trustworthiness, goodwill (Wrench \& Punyanunt, 2004), availability and interactions (Curtin, Stewart \& Ostrove, 2013), treating advisees as junior colleagues (Bieber \& Worley, 2006), and the ability to help the student 
graduate in a timely fashion (Lovitts, 2001).

The literature on how advisors make advisee choices on the other hand is practically non-existent. Barnes and Austin (2009) note that in general advisor perspectives are less studied than student perspectives. It may be reasonable to assume that advisors also engage in an assessment of student characteristics. Based on the responses from advisors in the area of Counseling Psychology in Knox et al.'s (2006) study, it is likely that advisors also consider the cost and benefits in advising a particular student before accepting or rejecting him or her. Examination of actual criteria applied by advisors is yet to take place.

Ray (2007) recommends that the assessment of criteria should be an objective process to arrive at the best choices. It appears that this does not happen in practice $-20 \%$ of graduate students in Goldberg's (2003) research said that they would choose a different advisor given a second chance even though they had the freedom of choice in the first instance. According to Ray (2007), this may be because they have incorrectly assessed the relative importance of each criterion to them or may not have had full information on the criteria. We posit that a third reason for this can be that both students and faculty are influenced by other factors which prevent them from making an objective assessment of the criteria and lead them to wrong choices. Therefore, in order to understand how advisor-advisee pairs are formed, it is not sufficient to identify the criteria applied; we also need to recognize the factors that affect the evaluation of such criteria.

\section{Influencing Factors}

Absence of sufficient research makes it difficult to predict which other factors affect advisor/advisee choices. We expect that factors related to faculty (e.g., gender), students (e.g., nationality), and departments (e.g., size) that have been found to affect faculty-student relationships might influence the choices.

\section{Faculty factors}

The impact of gender on perceptions about faculty members at research universities has been widely studied. Male faculty tend to fit into the stereotypical mold of the ideal academic/scientist better than female faculty, making the former more attractive as advisors than the latter. "Valued attributes of science - such as rationality and control - are attributed to men more than women" (Fox, 2001, p. 655), which affects women's credibility as scientists. In addition, although more women obtain doctorates and enter academia, their career growth is very slow and they remain under-represented in the higher ranks (Bilimoria, Joy, \& Liang, 2008). Students who may look at career progress as an objective process may interpret this gender disparity in faculty ranks as an indication of women's lack of competence. Under-representation at the top renders women less visible to students. This lack of visibility (Krefting, 2003) is compounded by their choice to survive in academia by being non-confrontational and invisible (Heinrich, 1995). In advising relationships, students may expect a male faculty member to provide help that is more practical in nature, and a female faculty member psychosocial help (Tenenbaum, Crosby \& Gliner, 2001) that is maternal in nature (Guiffrida, 2005; Heinrich, 1995). Although empirical evidence as to whether the actual help provided is in accordance with the expectations is inconclusive (e.g., Goldberg, 2003: Tenenbaum et al., 2001), the repercussions for violating the gender stereotypes are real. Students have reported feeling betrayed and deeply disappointed when these expectations are not met (Heinrich, 1995). Female faculty who do not fulfill gendered role expectations are reported to receive hostile responses in student evaluations (Sprague \& Massoni, 2005).

A relatively less researched feature of faculty that potentially impacts advising relations is faculty career stage. Junior faculty are considered inexperienced in many academic functions and in need of mentoring themselves (Feldman, Marshall, Lovett, \& O’Sullivan, 2010; Sands, Parson, \& 
Duane, 1991). Advising is one of the functions that they enter into without prior training and start doing based on their own experience as advisees (Knox et al., 2006) The senior faculty members, on the other hand, are more experienced in advising, although they also have had no training, but learned the task by doing it (Halse, 2011). Good advisers are thought to treat the advisees like a junior colleague or a peer-in-training (Bieber \& Worley, 2006) and junior faculty may do that more easily. The demands of the job are different for junior and senior faculty. Faculty availability is predicted to impact ability to graduate advisees faster (Curtin et al., 2013) - junior faculty facing tenure pressures may choose to maintain close contact with advisees whose work has publication potential, whereas senior faculty's service commitments may make them scarce. Despite such speculations, as far as we know, no empirical study has been done on the impact of career stage on advising, and which group the students find more attractive as advisors.

\section{Student factors}

American graduate schools attract the highest number of international students (Institute of International Education, USA, 2011; UNESCO's World Conference on Higher Education Report 2009). Advising international students could be challenging because of cultural differences, insufficient English language capabilities, and educational system differences (Charles \& Stewart, 1991; Curtin et al., 2013; Kim, 2007; Offstein et al., 2004). In advising relations, deficiency in linguistic capabilities limits exchange of ideas with the advisor and puts the advisee in need of much handholding from the advisor in the writing stage. Along with culturally rooted stylistic differences in communication (e.g., differences in relationship building styles, body language etc.), it could lead to interpersonal issues resulting from misunderstandings and make conflict resolution immensely difficult (Kim, 2007). Lack of familiarity with the US educational system and academic expectations is another big challenge that international students face, for which they may turn to the advisor for help (Zhai, 2004). Thus, compared to advising domestic students, advising international students becomes a more effortful and challenging activity that requires a broader range of skills.

However, despite the difficulties facing them, international students consistently show higher and faster degree completion rates compared to domestic students, Curtin et al. (2013) observe. The authors speculate that this difference may be because international students that travel to the US for graduate study are a self-selected group of the more talented and ambitious. In certain fields (e.g. Mathematics), they are believed to be better qualified than domestic students (Herzig, 2002). In graduate school, they are more concerned about receiving research related and professional development experience (Curtin et al., 2013) and attaining academic success (Zhai, 2004), which shapes their attitude and approach to graduate education. They possess a stronger sense of academic identity and find it easier to fit into the academic environment (Curtin et al., 2013). In comparison, domestic students often start graduate school wanting to emulate the idealized image and lifestyle of faculty that they formed during their undergraduate years, realizing only later that the faculty life is "unbalanced, work-centered and stressful" (Golde, 2005, p. 689). As a result, they find it difficult to meet the demands of graduate school and opt to leave (Golde, 2005).

In terms of expectations, international students accept their social isolation as a reality that they have to live with and do not expect to bridge the cultural and social gaps and build relations with peers or local people; the only relationship that they want to work is the one with the advisor (Rose, 2005).These students tend to have expectations about the nature of the relationship based on the models of student-teacher relations in their home cultures. In many cultures, especially from Asia, teachers are parental figures, and students from those cultures expect parent-like engagement from their American advisors (Charles \& Stewart, 1991; Dong, 1996; Kim, 2007). The relationship has been perceived to be less personal in the US and most US faculty do not offer assistance or go out of their way to help a student (Eland, 2001). When the advisor behavior does 
not match the expectation, the students perceive it as a lack of interest in them and they may feel rejected. The advisees place the responsibility to make the relationship work on the advisors and expect the advisors to initiate the steps for building it (Kim, 2007). The advisors, on the other hand, may interpret the advisees' reluctance to approach them as the lack of interest to work with them and may decide not to invite the student into an advising relationship (Friedman, 1987). Student nationality thus becomes a complex factor in the faculty's decision to accept or not accept a student as advisee.

\section{Departmental factors}

Academic departments are usually grouped into disciplines in empirical studies (Golde, 2005; Zhao et al., 2007). De Valero (2001) points out that this approach does not capture the variations among departmental policies and practices. It is observed that the department is the locus of control in doctoral education with each department forming its own policies regarding admission, financial support, and degree progress (Frazier, 2011; Zhao et al., 2007) and can have a significant impact on student experience and outcomes (Austin, 1996; de Valero, 2001).

Advising is an area for which departments often refrain from formulating common policies or guidelines and leave it to individual faculty members to carry out as they see fit, particularly when faculty grants are the source of funding (Fox, 2001). However, unwritten practices and norms for pairing advisors and advisees exist in every department. Zhao et al. (2007) describe that in some departments all students are assigned to an initial advisor as they begin the program and over the next year or so they are expected to form a relationship with someone else who then becomes the advisor. In other departments, students and advisors decide to work together during the admission process, or faculty choose students who they want to work with and admit them to the program. Another model of advisor matching is for departments to have students advised by a committee for the first year while they complete lab rotations. There are departments where students have to meet program milestones such as coursework and/or qualifying exams and prove their competence to be able to choose advisors. Students report that the faculty do not pay attention to them until they clear the milestones (Herzig, 2002). It is not uncommon to have lack of uniformity in practices followed in the same department, as a result of which the final pairing for different students in the same cohort gets done at different points, leading to anxiety and a sense of competition among the students. The stop-gap arrangements such as assigning of initial advisor or committee have not been found to be effective, as these advisors do not invest in the students knowing that they may not be the final advisors anyway (Herzig, 2002). Lack of orientation for students on the process leads them to rely on other students for guidance and support.

The size of the department/program is another factor that affects advisor-advisee pairing. Departments may have sub-groups based on areas of research, some with very few faculty members. This limits the choice of advisors for students whose research interests fall in those areas (Golde, 2005). Also, faculty find that they have to limit the number of advisees because of departmental regulations, lack of funding, or by the sheer impossibility of the task. Under these circumstances, students who do not make their choices early enough find themselves without advisors in their area of interest.

The incentives for advising vary among departments. Faculty tend to view teaching and advising related responsibilities as "load" (Hearn \& Anderson, 2002), especially in research universities, where teaching is less valued. Research shows that number of hours that faculty spend on advising has decreased considerably in the last three decades. In the absence of formal rewards, faculty are encouraged to take up advising only if it is accompanied by incidental rewards. These include getting qualified workforce for the lab, publication potential of the students' work, funding brought in by the students through grants or scholarships, and opening up of international re- 
search opportunities because of students' nationality or membership in certain research centers or joint ventures between students' and faculty's institutions.

\section{Purpose of Research}

As established in the literature review, the process of forming advisor-advisee pairs is often taken for granted and has attracted very little research focus, in spite of it being one of the most consequential decisions in doctoral life. It is necessary to understand the dynamics involved, to be able to create appropriate structures and processes or to improve existing processes. Hence, the primary purpose of our study was to gain perspectives from both graduate students and faculty members as to how they selected advisors and advisees and what common criteria were applied in this selection process. The second purpose of our study was to explore if and how factors pertaining to the faculty, students, and departments affected the evaluation of these criteria and adviseradvisee pairing. We adopted a qualitative exploratory approach since there is a lack of previous theoretical models.

\section{Methods}

\section{Sample and Data Collection}

This study was conducted in a private American university and was funded by NSF-ADVANCE Institutional Transformation Program for increasing the participation of women and minorities in science and engineering workforce. The doctoral students and full-time faculty members of all 31 Science, Technology, Engineering, and Mathematics (STEM) departments in the university that were part of the ADVANCE program were invited to participate in the study by email. Snowball sampling was used when the members of a special population (e.g., international students), proved difficult to recruit.

Given the exploratory nature of the research questions and the need to understand multiple perspectives, the data collection method chosen was focus groups (Kreuger, 1988). An interdisciplinary team of trained faculty and staff conducted six focus groups, one each for domestic graduate students, international graduate students, pre-tenure female faculty, pre-tenure male faculty, tenured female faculty, and tenured male faculty. Additional individual interviews were carried out with international students (due to cultural reasons some of the volunteers felt more comfortable sharing their opinions in an individual setting than a group setting) and tenured female faculty (it was difficult to schedule the focus group at a time that was suitable for all volunteers). Combining focus groups and individual interview data to augment data richness in similar settings was done also by Offstein et al. (2004). Prior to the beginning of focus groups and interviews, participants were asked to complete a brief demographic background questionnaire. During focus groups, participants were asked to describe the process followed for pairing students and advisors, and to discuss the impact, if any, that factors such as student national origin, gender, and faculty status might have had on this decision. The same protocols were used for individual and group sessions. The focus groups and interviews were audio-recorded and then transcribed into electronic documents.

\section{Participants}

A total of 17 graduate students ( 7 males and 10 females) and 35 faculty members (19 males and 16 females) participated in this study. Participants in the domestic student focus group (4 males and 6 females) had an average of 4 years of experience in their graduate program. The international student participants ( 3 males and 4 females) had an average of 3 years of experience in America and 2.4 years of experience in their graduate program. The faculty participants included 
9 pre-tenure/junior females, 6 pre-tenure/junior males, 10 tenured/senior females and 13 tenured/senior males. Taken together, the 33 faculty members had an average of 11 years of teaching experience at this university (demographic information was unavailable from 2 faculty members).

\section{Data Analysis}

NVivo 7.0 was used for coding and grouping the themes. The researchers individually analyzed the transcripts to identify the common patterns and themes. The researchers then met as a group and differences were discussed until consensus was reached. As themes evolved, transcripts were analyzed again in an effort to challenge, expand, and refine the thematic categories. Researchers also examined the codes to see if there was sufficient differentiation between themes, and combined the codes that were similar. The process was iterated several times until the list of categories appeared to be both parsimonious and complete. The final coding structure, which consisted of both broad themes and their dimensions, was then applied to the entire set of transcripts. Quotations from participants also were identified, including key words or phrases that captured the essence, or served as metaphors, for a theme.

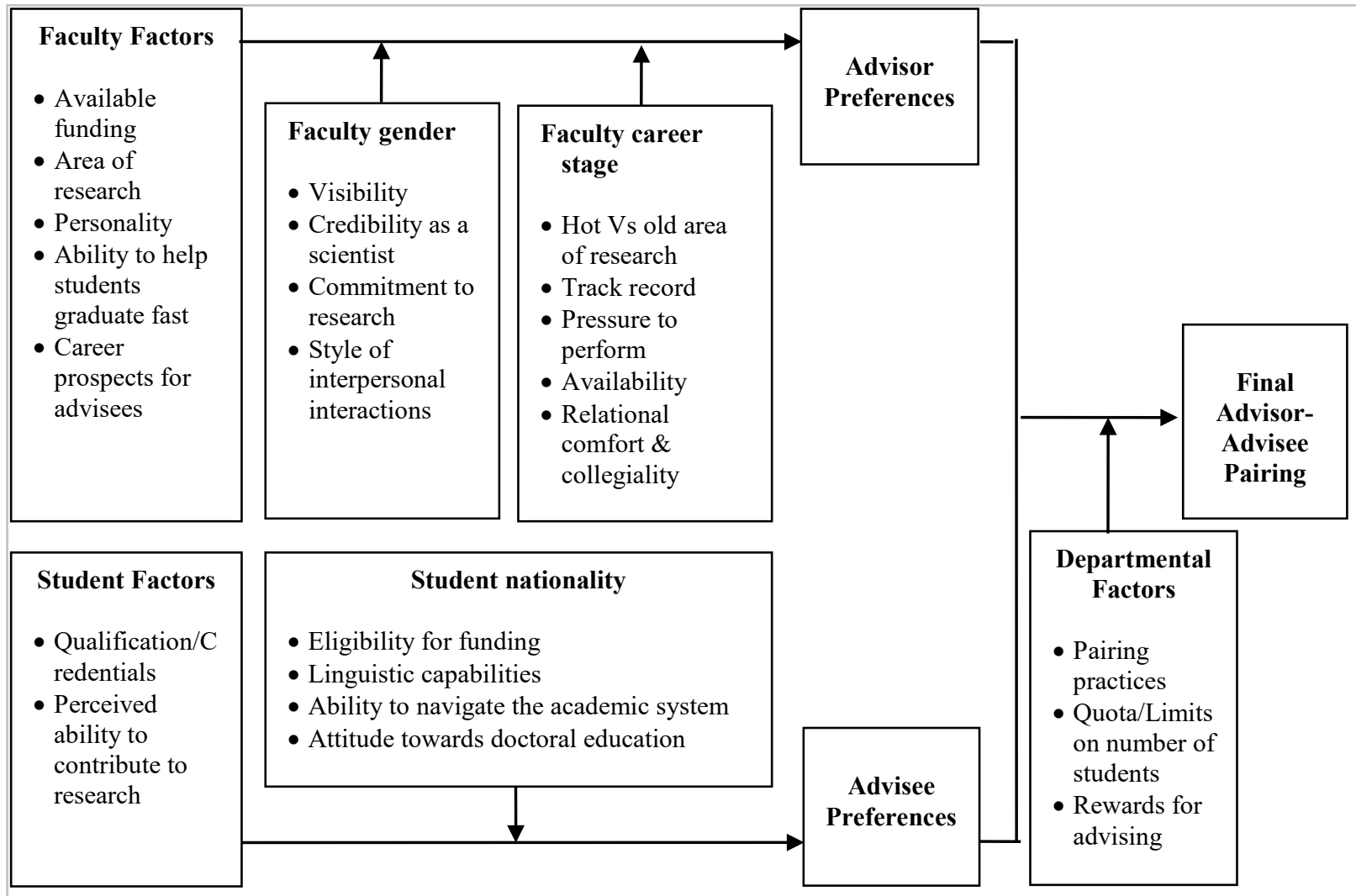

Figure 1. Empirical Model of Advisor-Advisee Pairing

\section{Findings}

The data confirmed that advisor-advisee pairing involved a decision process in which the students as well as the faculty considered many factors (Figure 1). We found that stereotypes around the gender and the career stage of the faculty member and the nationality of the students biased how they were evaluated on the above mentioned factors. In addition, Departmental Factors were crucial in determining if the advisors and advisees were actually assigned to the ones they preferred. 


\section{Faculty Factors}

In selecting a potential advisor, several features of the faculty were identified by both faculty and student participants as critical as discussed below.

\section{Available funding}

Funding was perceived by participants as perhaps the most important factor in attracting graduate students. The majority of student participants believed that "most graduate students chose their advisor because of funding." Both domestic and international students mentioned that some students had changed their research interests to work with advisors who could fund them. A domestic student noted "sometimes there might not be a match between what student is interested in and the funding that's available. And that's where students find themselves working on something they 'have to' - to get funding - and working without passion." Faculty participants also confirmed that "generally graduate students do not go to a program unless they are assured that they will be funded" [A tenured female faculty].

\section{Areas of research}

A faculty member's research area was recognized as important as funding in identifying an advisor. "I picked my advisor solely because of the research interest" a domestic student said. The faculty concurred. "I think that certainly the primary or the first thing that the students think about is the research topic" [A tenured male faculty].

Students and faculty participants also noted that graduate students tended to be attracted towards the latest topics in the field. "There are always fads in any field, and there are these 'in' areas. And if a faculty member happens to do work in area that is 'in' at the moment, he or she attracts students" [a tenured female faculty].

However, some students expressed the desire to establish their own identity in the chosen area and a voice that is distinct from their advisor's, and wanted advisors who would help them with that. "I was clear about not being someone's clone. I wanted to find someone that would support that. To use participant J's words, owning my own voice and having that voice supported" [A domestic student]. Some of the faculty were sympathetic to this view. "Some students feel that they are being groomed to be the clone of their mentor and it's very scary to say hey, I don't wanna be like you. I wanna be like somebody else now" [A tenured female faculty].

\section{Personality}

Students were sensitive to the personalities of the faculty they chose to work with. "Nice," "open," "easy going," "not aggressive," "confidence", "trustworthy" and "comfort level" were the words used by participants to describe the personality of a desirable advisor. Faculty participants perceived that the "comfort level with a particular person the students would like to work with ranks pretty high in their consideration once they start to know people here" [A tenured male faculty]. A mismatch in personality and work habits was raised as a reason to change advisor. "The things that work with some people would not work with me. He [former advisor] was confrontational and he set specific deadlines and had very specific rules. I'm more of a 'I'll do it, just give me some time' kind of person. The other professor [current advisor] is more like 'what are you doing?. He makes sure you are on the right track and getting your work done. He's much more open. His students do not graduate as quickly because he is much more open. But I think the environment is nice" [A domestic student]. 
Joy, Liang, Bilimoria, \& Perry

\section{Ability to help students graduate fast}

Past performance of an advisor in getting students graduated was perceived by both student and faculty participants as critical in advisor choice. The average number of years that the advisees of a certain faculty took to graduate was an important criterion while deciding whether to choose them as advisors. "I chose the particular advisor because they are known to get students out of the door, and I didn't want to hang around much longer than I had to" [A domestic student]. Faculty participants also were cognizant of this fact. "I have overheard in discussions that some students choose their advisors' labs according to where it is easier to get projects done" [A pretenure male faculty].

\section{Career prospects for advisees}

Participants from both student and faculty groups noted that graduate students chose their advisor based on a faculty member's perceived ability to advance the student's career. "When you're done with your graduate program, you want someone who can advance you, either in a post doc or job application" [An international student]. The students looked at where their predecessors obtained jobs and were interested in finding out if the reputation, credibility, and the network of the advisors would be helpful for them. "Being with a faculty member who has tenure and prestige that's really where you want to be. Partly because of the next step [getting a job], the bigger the name the easier it is " [An international student]. The students were concerned about associating with faculty that had negative reputations.

\section{Influence of Faculty Gender}

Though some said that gender had no impact when there was a match in the research interests or when the faculty member had a name in the field, other participants observed female faculty had lesser number of advisees. "From my own experience, I've had, until this year, more money than I've been able to get students for and I have not been able to just get them to even come to the door" [A pre-tenure female faculty]. Comments by the participants alluded to the existence of gender stereotypes. Women faculty in departments with lesser number of women experienced gender effects more severely.

\section{Visibility}

According to a few, female faculty were less visible in the department in comparison to their male counterparts. "In my department, there are two senior female faculty and they have the least number of students. I haven't really spoken much to the couple of females [faculty] and I don't know what the relationship [between them being females and having the least number of advisees] is. But it is telling that the younger male faculty probably aren't in the category of people who could do a better job of really pushing you along in your career, but they do seem to be doing a better job of getting students into their labs, and that would be beneficial to your career because they have higher visibility" [An international student].

\section{Credibility as a scientist}

Some participants speculated that female faculty (especially at the junior level) did not fit the students' conception of an 'ideal scientist' and hence were perceived to be less qualified to guide students: "I believe that the students are more willing to trust their [male faculty] scientific judgments or, you know, go to them [male faculty] for scientific advice than they would for a female" [A pre-tenure female faculty]. "I think, for female faculty, I don't mean the general, but for my advisor [specifically, who is a junior faculty], she believes her idea very firmly and it's very hard to persuade her that we go another way. [The result is that] Sometimes, she is right. But sometimes, I am not sure [An international student].” 


\section{Commitment to research}

Both faculty and student participants pointed out that female faculty were perceived to be less research-focused because of their family roles. "... my male colleague was saying to the student 'why are you asking me if I can come up with a project that suits your interest when we have someone in the department who does what suits your interests' and the student said 'Women don't work as hard, they don't care as much about their science, they care about their families first and they don't put in as much time "' [A pre-tenure female faculty]. There was the impression that this mindset was stronger among some international student groups. "This past year one of the international students told one of my male colleagues that the international students didn't want to work with women because they were going to have babies and weren't going to pay as much attention to the lab" [A pre-tenure female faculty].

\section{Style of interpersonal interactions}

Female faculty were aware that they might disappoint students in not being feminine, maternal, and nurturing in interpersonal interactions. "I got a whole group of people who thought I was going to be very nurturing, which unfortunately I'm really not. I mean, I don't do that very well. So I had experiences, mostly with female students, where I had one in particular that I ended up having to get rid of her out of my lab, because she wanted to talk about earrings and laundry and oh my God and I was like, 'do some science,"' [A pre-tenure female faculty]. While some felt that female faculty were more nurturing towards female students, the others felt that they were tougher with female students. Examples of female faculty offering special advice to female students as well as female faculty and female students not wanting to work with each other were offered.

\section{Influence of Faculty Career Stage}

The tenure status/career stage of the faculty member was discovered to be pivotal when students made judgments about several of the faculty features. Junior and senior faculty were thought to be different in many respects.

\section{'Hot' versus "old” areas of research}

It was felt that the junior faculty carried out their research in new and cutting edge topics compared to the senior faculty. This added a 'hotness factor' to the junior faculty and made them more appealing. An international student participant observed "some senior faculty members whose research was in the 1960s, they basically teach unpopular required courses that someone has to teach, and they are kind of seen as only doing that, not much [new] research" [An international student].

\section{Track record}

Students often found the lack of a track record a problem with faculty at early career stages. A pre-tenure male faculty member admitted "sometimes junior faculty are seen by students as not having proven already that they can produce papers at such a pace, so they might choose a lab that has proven already that students don't have any problems in producing the papers". Junior faculty were considered to have fewer resources and fuzzier research agendas compared to senior faculty. "Many young faculty that are pre-third year review [mid-term review in tenure process], they are just starting out, they do not have all of their equipment yet, they may be a little bit scattered in terms of what types of projects that they are doing " [A tenured male faculty]. 
Joy, Liang, Bilimoria, \& Perry

\section{Pressure to perform}

Pre-tenure or junior faculty were perceived by student participants as facing more pressure than tenured faculty in meeting the performance criteria as a result of their tenure track status. This in turn might impact how demanding they would be as an advisor. "For the tenured advisor, they do not work very hard. Based on my personal understanding, some tenured faculty do not work hard. I don't mean that they don't care [about] the students. But they don't [put] pressure on the students. So the progress of the project totally depends on the students. But for the non-tenured advisors, they themselves have high pressure. And they need immediate progress on the project, so that they can publish paper, they can get patent, finally they can get funding from different foundations, so that they can get tenured. These pressures make them push students usually harder than the tenured advisors. In this case, most grad students in the non-tenured advisor's lab have higher pressure. These higher pressures also give them higher/more production [productivity]" [An international student]. However, some of the student and senior faculty participants felt that advising would be an additional pressure on the junior faculty. "I see a lot of pressure in our area on junior faculty in terms of getting tenured. I don't want to put unnecessary the burden of being the chair of a student committee on them because they have a workload on them to maintain" [A domestic student].

\section{Availability}

Another notion was that the junior faculty spent more face time with students in the lab and in their offices than the senior faculty. Senior faculty were perceived to have more committee work and other service commitments that reduced their availability to students. "Senior faculty members are the ones who are in all the high committees and may have meetings all day. So it's like, if you work with this guy, he is busy all the time. But he is a senior guy and he is almost on every committee. But if you want time [with the advisor] you work with junior faculty who have time" [A domestic student]. This was confirmed in the male faculty focus group interviews. " ... as you move up in the ranks, committee seems to take more and more of your time away and consequently you don't have as much time to interact with the student" [tenured male faculty].

However, the students were sceptical about the long term availability of junior faculty since there was the risk of their not getting tenured and leaving the school. "If you want to work for an untenured faculty or junior faculty there's a high risk that they're not going to be there for the duration of your PhD...there's a very short window of opportunity with junior faculty." [An international student].

\section{Relational comfort and collegiality}

Participants also noted that junior faculty were perceived to have "a lot in common with students" since they were close in age and experience and the interactions with them were more "collegial" and "comfortable". An international student commented "our department is growing quite rapidly and we have more junior faculty who are in their early to mid-thirties and they're a lot more available, more open to discussing a wide range of topics. They don't have as many responsibilities as the other faculty, and they have a lot more current, recent experience that they can give to you. So they're like, five years ago I was where you are, this is how I got where I am now, whereas a lot of the older faculty, in terms of science, graduated when it was a completely different world, and when they got their PhDs the career paths were so different". Student as well as senior faculty participants observed that the energy around the junior faculty made them attractive to students. "The junior faculty were the most interested and the most dynamic, and everyone wanted to work with them" [A domestic student]. 


\section{Student Factors}

Some features of the students that the faculty examined affected their preferences for and acceptance of them as advisees. The main features that both the faculty and student participants reported included the following.

\section{Student credentials}

While assessing the credentials of students, the faculty took note of standardized test scores and/or qualifying exams as well as students' skill sets and experience. "A lot of my work involves certain skills, and previous experiences are helpful in judging whether that student will be successful, and so it's a combination of the student applying to the program to work specifically with a faculty member and the faculty member looking at the set of applicants interested in working with them and selecting one that provides the highest potential, matched with their interest area" [A tenured female faculty]. Another important criterion of the student credentials was the score in the qualifying examination.

\section{Ability to contribute to research}

The faculty participants also were concerned with the ability of the student to contribute to research meaningfully. The student participants pointed out that some of the faculty were interested in making sure that the students contributed to the faculty's own area of research. "In the years since I entered, he [the advisor] has chosen a very narrow path of research, and the impact that has had on his career is that he is now recruiting just those students who want to work in his narrow field of interest. I am the last student who is not doing work in this particular line of research. Although he has tried to mold my interest but I have been very firm on that I don't want to work on that. When he accepted me it was based on my qualification and my research interest at that time, but now he is only taking students interested in this particular area, and thus when student work, they obviously indirectly help him to advance in his field" [A domestic student].

\section{Influence of Student Nationality}

Many faculty and student participants considered the nationality of the students to be a factor in the advisor/advisee selection process and a predictor of their doctoral performance. Tokenism was observed in admitting international students. Performance of existing international students was usually discussed while making decisions about accepting their fellow nationals. A few faculty members openly said that they did not accept students from certain countries because of negative experiences in the past.

\section{Eligibility for funding}

Both student and faculty participants observed that eligibility requirements limited funding opportunities for international students. A tenured woman faculty member shared her own experience: “...it looks like bias, but it is not so much bias as it is practical, because there is a lot of funding available to us to fund the students, but it is limited to US citizens or permanent residents. We get a lot of engineers from, a lot of capable students from outside the country, but we may very well say 'no' to them in favor of the US students. This is a tricky thing but that is how it works".

\section{Linguistic capabilities}

Many suspected that the language was a barrier to effective advising of students from certain countries and sometimes resulted in misunderstanding and conflicts. "I've really struggled, I've had students of [lab] rotations and it's never really been clear to me whether the student fully 
understood things that I might have said, so there is this big communication gap with students from Asian countries as was said earlier. It's quite as true that if you're getting students from Europe or India, they actually have a better command of English [than even the domestic students] " [A tenured male faculty]. It was felt that faculty had to take special measures to address the international students' unfamiliarity with language and culture in the US. "...I think the faculty had to just be very sure that the students were understanding exactly what was expected and directions. They did require a lot more interaction in terms of writing up their research, pretty much a fundamental skill development in respect to writing" [A tenured female faculty].

\section{Ability to navigate the academic system}

The international students were perceived to be "more naïve" and as "lacking awareness of the elements of the educational system and academic structure in the US" (such as selecting the right courses, grading, and tenure system). Domestic students were viewed as more "sophisticated" in understanding the system and negotiating relationships than the international students. "Domestic students are more sophisticated in the sense that they probably get better socialized, I mean they learn to think and look for the fact" [A pre-tenure female faculty].

\section{Attitude towards graduate education}

It was felt that the international students had a greater appreciation of their education, saw graduate school as a privilege, and were very focused. Domestic students were perceived to enter graduate school with a sense of entitlement, but with a lesser sense of purpose. "For the right reasons or the wrong reason I think that many of the non-domestic students actually come with a singleness of purpose, to get the degree. And many, not all, domestic students come because they don't know what else to do after college. And they're just sort of continuing along, and maybe they'll get something figured out" [A pre-tenure female faculty]. International students were seen as more hardworking while the domestic students were assumed to be more concerned with "lifestyle". "The only thing that I actually see at least for us that's a bit different now is that, for a lot of what we refer to as the domestic or the US students, they're beginning to get a little bit more 9-5 ish, whereas most of the international students, perhaps based on the training and what they had to do to get out of their countries and into a US school, are actually much more aggressive, and often they're the folks you'll find there early and they're the folks you'll find there late" [A tenured male faculty].

\section{Departmental Factors}

Even when both faculty and students had preferences as to who to work with, departmental factors were found to influence if they were actually paired with their preferred ones.

\section{Prevalent pairing practices}

In some departments pairing was done before or during admission, and in others after admission. At each of these time periods, the extent of information on various selection factors available to both faculty and students varied, and so did the sources of information. As a result, factors that influenced the decision varied depending on time of pairing.

In cases where pairing was done before admission, research interests and student credentials were regarded as the most important criteria. The students usually came in wanting to work with a specific advisor, having read about the advisor's interests, and contacted them via email or in conferences. The choice was solely guided by match in research interest. "I actually picked my advisor before coming here. I was interested in a particular field of research. I did my own research to find the best people in that particular field. I contacted him. As it turns out he was looking for a 
student and he saw some match in me. So I didn't know a lot about the personality. I knew about the research. I didn't visit him or the lab" [A domestic student]. Research interest based pairing was also done by the admissions team as part of the admission process. "In our department, we actually bring students in and we have an interview process where we actually select. So there's some knowledge face-to-face of the person and their [research interests]. And then before they join there's a match[ing process]. So we have them assigned to an advisor largely based upon potential research interests overlap and also partly based upon faculty availability" [A pretenured male faculty]. Some student participants perceived the pairing process to be very fluid and unclear, and were not fully satisfied.

The advisor choices made after admissions were guided more by personality and track record of the faculty with other students, and the advisee choices by students' perceived research ability. This process was informed by the interactions they had with each other mainly during formal lab rotations and/or classroom lectures. "If the students come in without a preconceived notion of who they want to work with and then in that case, it is strongly influenced by who they get to interact with" [A tenured male faculty]. Students were strongly influenced by the information (and sometimes misinformation) on faculty that spread through student grapevine. "I don't think we make individual decisions about faculty. In our department whenever I have interaction with faculty I tell someone about it and we give feedback. A couple of us actually started a club called 'Strange encounter with academia' and every time something weird happens we share it" [A domestic student]. The faculty were sensitive to the impact that disgruntled students had on such information sharing and felt that it negatively affected objective assessment of faculty personality and credentials.

\section{Quota or limits on the student numbers}

Some departments had restrictions on the number of advisees per faculty. Though these restrictions arose out of the good intention to avoid piling up students in certain labs or with certain faculty members, it was perceived by faculty participants as sometimes limiting their own as well as students' choices. "It gets a little bit difficult in my department because faculty are limited to number of students that they can take. So if you have students [who] do rotations and you already have your quota - and we are only allowed to have 2 students at a time - then even if they wanted to come and join your lab, we are not allowed to take them. So in those situations students do often end up having out of necessity to go work with someone that they may not necessarily have been their first, second or even third choice, but that they were forced into that environment because they was no other option" [A pre-tenure female faculty]. There were some programs that restricted the number of international students that they admitted due to funding constraints.

\section{Rewards for advising}

Training advisees was an activity that was not always rewarded positively, especially in the case of pre-tenure faculty. The reward structure is such that it works as a punishment if the faculty member does not train a specified number of students. "I had a most recent student, a good one who wanted to leave. He had some self-confidence issues, maybe didn't think he deserved a masters. I was approached by our program director and our chairman saying, 'You find a way to get this guy a masters because it's important for your career that he has a degree of some sort and doesn't just leave the program'" [A pre-tenure male faculty]. Pre-tenure faculty felt they were at a disadvantage as sometimes the bad students were thrust on them. 
Joy, Liang, Bilimoria, \& Perry

\section{Discussion}

Based on the findings from this qualitative exploratory study, we offer a beginning model of the advisor-advisee pair formation (Figure 1). It reveals that individuals form their preferences based on a number of criteria, however preference formation is far from an objective process as they are influenced by their perceptions of each others' characteristics (such as gender, career stage, nationality). It also shows that final pairing is beyond individual control because of the influence of departmental elements.

Students find the faculty members' ability to provide funding, area of research, personality, ability to graduate students quickly and impact on students' future careers as the criteria to determine whether they will make good advisors. These findings are consistent with the criteria revealed in the survey study by Zhao et al. (2007). Both sets of findings show that students possess developmental as well as pragmatic orientations. The developmental orientation is observable in their concern with match in area of interest in our study and intellectual compatibility in Zhao et al.'s (2007) study, and the pragmatic orientation is evident in a focus on ensuring funding and timely completion and even the forethought to capitalize on the advisory relationship to build a future career. Individual students however vary in the relative importance they attach to each of these criteria as found by Ray (2007) as well, especially availability of funding and match in research interests, which are considered the most important among all criteria. While some students feel that a match in research interests is non-negotiable, for others it is funding that is non-negotiable. It is yet to be seen how the prioritization may change in the future considering the funding cuts and academic job market following the global recession.

This study is one of the first to explore what advisors look for in their advisees and finds that they are most concerned about advisees' credentials and ability to contribute to research. We feel that this concern factors into how faculty assess the costs and benefits of advising. In a study by Knox et al. (2006) of advisors in the area of counseling psychology, the advisors claim that the benefit of advising is personal satisfaction and the cost is the time demands. They say that positive professional characteristics of the advisee contribute to advisor satisfaction. Advisors' concern with credentials of the advisee discovered in our study may be part of their efforts to ensure that the advisee possesses desired professional characteristics before they commit to the relationship, and thus will contribute to a satisfactory overall relationship. Similarly, their concern with the ability of the advisee to contribute to research may have origins in their wish to minimize the time and effort spent on advising. Further, an advisee with research potential may turn out to be a good collaborator (Wang et al., 2010) and help to advance the advisor's career. In science, this is especially true as students are the key resources to take faculty projects forward.

Another key finding of this study is that the assessment of these criteria is a very subjective process, as individuals are influenced by several factors. The factors that emerge as salient include faculty gender, faculty career stage and student nationality. It might not be surprising that women faculty are looked at less favorably as potential advisors given the systematic bias against women in seemingly objective processes in other aspects of academic life (Bilimoria et al., 2008; Valian, 1999). Even when there is funding and match in research interests, women find it difficult to get advisees, since students tend to rate them lower on their ability to graduate students faster and advance their careers, because of the perceptions about their credibility as a scientist, commitment to research, and visibility (Fox, 2001). Personality clashes may have to be anticipated with women faculty when they do not display the stereotypical maternal/gendered behavior (Sprague \& Massoni, 2005; Superson, 1999). Larger proportion of women in a department does make a difference (Fox, 2001), as the assessment of potential advisors seems less gendered in such departments. Our study articulates stereotypes about faculty career stage which are not explored in previous studies. Unlike gender, career stage does not attract a universally positive or negative 
response. Junior faculty are favored for research interests and collegiality, while their pressure to perform and short versus long term availability invoke ambivalent reactions. The established careers of senior faculty make them look like dependable advisors who can provide funding and good career opportunities, while their availability is seen as an issue (Macfarlane, 2011). It is possible that gender and career stage will have interaction effects, which may put junior women faculty in the most disadvantageous positions in attracting graduate students.

When it comes to assessing criteria related to students, nationality is a source of real constraints as well as stereotypes. Student's eligibility for funding is a structural constraint that the advisor may feel helpless about. The level of linguistic capabilities is seen as affecting a student's ability to contribute to research (Kim, 2007). The lack of familiarity with the academic system among international students may require additional advising efforts from the advisor (Zhai, 2004). The perceptions about work ethic may give international students an edge over the domestic students, but it could also lead to situations of exploitation. The tokenism in decision making is an indication of discrimination that goes unreported.

In spite of the individual preferences, the final paring is dependent on the structural constraints posed by departmental factors such as prevalent pairing practices, restrictions on the number of advisees per faculty, and rewards for advising. The pairing practices determine the nature of information used for decision making. While pairing before or during admissions is based just on a match in research interests (Golde, 2005; Zhao et al., 2007), the pairing after admissions gives both faculty and students a better understanding of other factors as well. Golde (2005) discovered that in departments where pairing practices allow students to have long term interactions with the advisors (e.g., lab rotations) and thus more opportunities to develop a good sense of advisor's research interests and supervisory styles, student attrition rates were lower. Restrictions on advisee numbers are especially problematic in departments where faculty depend on students to carry out research related tasks, affecting their productivity. Unlike departments that are small or with less number of faculty in each interest area that have real manpower constraints (Golde, 2005), these regulations here create artificial constraints that help neither faculty, nor students, though the intention is quite the opposite. Lack of adequate rewards is seen as discouraging faculty from accepting advising roles (Hearn \& Anderson, 2002). In general, there is a sense of lack of clarity and transparency about departmental factors, which proves to be stressful for both faculty and students, and points towards the need for formal orientation and support structures (de Valero, 2001; Fox 2001).

\section{Implications for Research}

This study is a contribution to the slowly emerging literature on the advisor-advisee relationship formation. By inductively identifying the students' criteria for advisor selection, our findings verify the results from Zhao et al.'s (2007) deductive work. In addition, this study identifies the criteria applied by faculty in assessing potential advisees. Another key contribution of this study is in revealing for the first time how various faculty and student factors create perceptions that affect individual choices. It also shows how departmental factors become constraints in the process. The resulting empirical model establishes advisor-advisee pair formation as a process that involves various actors with different goals, making their decisions under a range of influences and constraints.

There are however limitations to this study, which open avenues for future research. Although the qualitative approach has helped us to have a well-rounded understanding of a number of factors that have bearing on this decision making process, it is possible that such understanding may be the result of post-hoc sensemaking of the participants. It cannot be conclusively said that students in the pre-selection phase may have had the same level of understanding about these factors.

Comparison of the mental models of students in the pre- and post-selection phases may be an in- 
teresting line of enquiry. Another possibility for comparison is between different groups (e.g., male/female/junior/senior faculty, domestic/international students, departments with similar processes) to see if there are similarities in the relative importance given to the criteria and/or perceptions in operation. Finally, our research focused on STEM departments within a single university; future research should compare and contrast the practices occurring across multiple universities. Quantitative models will be useful in producing more generalizable findings.

\section{Implications for Practice}

We join other researchers (de Valero, 2001; Fox, 2001; Golde, 2005; Kim, 2007) in emphasizing the need for orientation and support. Instead of the hands-off approach (Fox, 2001), we suggest that departmental administrators and senior faculty leaders design and implement systems and support structures to help both students and faculty members make more informed choices about the advisor-advisee selection. We recommend the following.

\section{Enhance clarity in departmental policy}

Departments should undertake a review of the extant processes used by students and faculty to make advising decisions, and determine steps to make the process of selection more equitable, transparent, and participative. Departmental guidelines and timelines for advisor/advisee selection need to be articulated.

\section{Implement an orientation for students}

A recurring theme in the findings is the need for orientation for graduate students, especially international students, on how to navigate through graduate school. Students may find it useful to have formal information sessions on how to choose an advisor, rather than having to rely on the opinions of other students. An information session would be a venue for not only talking about the factors that students should consider and the processes that they could follow, but also for creating awareness about various stereotypes that might subtly bias the decisions. Appointing a faculty member or peer guide/resource person in each department for students to talk with if they are finding the decision difficult may be a good follow up measure.

\section{Make faculty information available to students}

In the absence of rich information about faculty members, the student grapevine takes over. Departments vary widely in the amount of faculty information shared on departmental web pages and brochures. There should be avenues to distribute complete and accurate information about the faculty research interests, current research projects, research assistants, sources of funding, list of publications, future projects, etc. In departments that do not have opportunities for arrangements like lab rotation, there should be alternatives to enhance student-faculty interactions such as 'meet-the faculty' seminars where each faculty presents his/her research to the new cohort of students. Department socials also may be good idea (Golde, 2005).

\section{Provide support to faculty}

The faculty who have had to learn advising by doing (Knox et al., 2006) may find formal training on advising useful. They also might appreciate open discussions about their student resource needs, advising rewards, and measures to assess the effectiveness of advising. This may be a sensitive issue for discussion, and the chair and senior faculty leaders should ensure that junior faculty members have voice in this discussion. 


\section{References}

Austin, A.E. (1996). Institutional and departmental cultures: The relationship between teaching and research. New Directions for Institutional Research, 90, 57-66.

Barnes, B. J., \& Austin, A. E. (2009). The role of doctoral advisors: A look at advising from the advisor's perspective. Innovative Higher Education, 33(5), 297-315.

Bieber, J. P., \& Worley, L. K. (2006). Conceptualizing the academic life: Graduate students' perspectives. The Journal of Higher Education, 77(6), 1009-1035.

Bilimoria, D., Joy, S., \& Liang, X. (2008). Breaking barriers and creating inclusiveness: Lessons of organizational transformation to advance women faculty in academic science and engineering. Human Resource Management, 47(3), 423-441.

Charles , H., \& Stewart, M. (1991). Academic advising of international students. Journal of Multicultural Counseling and Development, 19, 173-81.

Curtin, N., Stewart, A. J., \& Ostrove, J. M. (2013). Fostering academic self-concept advisor support and sense of belonging among international and domestic graduate students. American Educational Research Journal, 50(1), 108-137.

de Valero, Y. F. (2001). Departmental factors affecting time-to-degree and completion rates of doctoral students at one land-grant research institution. Journal of Higher Education, 72(3), 341-367.

Dong, Y. (1996). A cross-cultural relationship between the advisor and the advisee: Dissertation writing supervision in science. ERIC Document Reproduction Service No. ED 394331.

Eland, A. J. (2001). Intersection of academics and culture: The academic experience of international graduate students. Unpublished doctoral dissertation.

Feldman, P. A., Marshall, S. J., Lovett, M., \& O'Sullivan, P. (2010). Does mentoring matter: Results from a survey of faculty mentees at a large health sciences university. Medical Education Online, 15, 50635071.

Fox, M. F. (2001). Women, science and academia: Graduate education and careers. Gender and Society, $15(5), 565-666$.

Frazier, C. C. (2011). Organizational change in academic programs: A case study of doctoral students' experiences. (Unpublished doctoral dissertation). University of Minnesota.

Friedman, N. (1987). Mentors and supervisors. IIE Research Report No.14.

Goldberg, E. R. (2003). The contribution of advisor behaviours to measures of graduate student success and satisfaction. (Unpublished doctoral dissertation). University of Western Ontario, Ontario, Canada.

Golde, C. M. (2005). The role of the department and discipline in doctoral student attrition: Lessons from four departments. The Journal of Higher Education, 76(60), 669-700.

Guiffrida, D. A. (2005). Othermothering as a framework for understanding African American students' definitions of student-centered faculty. The Journal of Higher Education, 76(6), 701-723.

Halse, C. (2011). Becoming a supervisor: The impact of doctoral supervision on supervisors' learning. Studies in Higher Education, 36(5), 557-570.

Hearn, J. C., \& Anderson, M. S. (2002). Conflict in academic departments: An analysis of disputes over faculty promotion and tenure. Research in Higher Education, 43(5), 503-529.

Heinrich, K. T. (1995). Doctoral advisement relationships between women: On friendship and betrayal. The Journal of Higher Education, 66(4), 447-469.

Herzig, A. H. (2002). Where have all the students gone? Participation of doctoral students in authentic mathematical activity as a necessary condition for persistence toward the Ph.D. Educational Studies in Mathematics, 50, 177-212. 
Institute of International Education, USA. (2011). Open Doors fact sheet. Available at http://www.iie.org/en/Research-and-Publications/Open-Doors

Jones, M. (2013). Issues in doctoral studies-Forty years of journal discussion: Where have we been and where are we going? International Journal of Doctoral Studies, 8, 83-104. Retrieved from http://ijds.org/Volume8/IJDSv8p083-104JonesFT129.pdf

Kim, Y. (2007). Difficulties in quality doctoral academic advising experiences of Korean students. Journal of Research in International Education, 6(2), 171-193.

Knox, S., Schlosser, L. Z., Pruitt, N. T., \& Hill, C. E. (2006). A qualitative examination of graduate advising relationships: The advisor perspective. The Counseling Psychologist, 34(4), 489-518.

Krefting, L. A. (2003). Intertwined discourses of merit and gender: Evidence from academic employment in the USA. Gender, Work \& Organization, 10(2), 260-278.

Krueger, R. A. (1988). Focus groups: A practical guide for applied research. Sage Publications.

Lovitts, B. E. (2001). Leaving the ivory tower: The causes and consequences of departure from doctoral study (1st ed.). New York: Rowman and Littlefield Publishers.

Macfarlane, B. (2011). Professors as intellectual leaders: Formation, identity and role. Studies in Higher Education, 36(1), 57-73.

Offstein, E. H., Larson, M. B., McNeill, A. L., \& Mwale, H. M. (2004). Are we doing enough for today's graduate student? International Journal of Educational Management, 18(7), 396-407.

Ray, S. (2007). Selecting a doctoral dissertation supervisor: Analytical hierarchy approach to the multiple criteria problem. International Journal of Doctoral Studies, 2(1), 23-32. Retrieved from http://www.ijds.org/Volume2/IJDSv2p023-032Ray18.pdf

Rose, G. (2005). Group differences in graduate students' concepts of the ideal mentor. Research in Higher Education, 46, 53-80.

Sands, R. G., Parson, L. A., \& Duane, J. (1991). Faculty mentoring faculty in a public university. The Journal of Higher Education, 62(2), 174-193.

Schlosser, L. Z., \& Kahn, J. H. (2007). Dyadic perspectives on advisor-advisee relationships in counselling psychology doctoral programs. Journal of Counselling Psychology, 54(2), 211-217.

Sprague, J., \& Massoni, K. (2005). Student evaluations and gendered expectations: What we can't count can hurt us. Sex Roles, 53(11-12), 779-793.

Superson, A. M. (1999). Sexism in the classroom: The role of gender stereotypes in the evaluation of female faculty. APA Newsletters: Newsletter on Feminism and Philosophy, 99 (1).

Tenenbaum, H. R., Crosby, F. D., \& Gliner, M.J. (2001). Mentoring relationships in graduate school. Journal of Vocational Behavior, 59, 326-341.

UNESCO. (2009). 2009 World Conference on Higher Education: The New Dynamics of Higher Education and Research for Societal Change and Development. ED.2009/CONF.402/2. Paris, 5 - 8 July.

Valian, V. 1999. Why so slow? The advancement of women. Cambridge, MA: MIT Press.

Wang, C., Han, J., Jia, Y., Tang, J., Zhang, D., Yu, Y., \& Guo, J. (2010). Mining advisor-advisee relationships from research publication networks. In Proceedings of the 16th ACM SIGKDD international conference on Knowledge discovery and data mining (pp. 203-212). ACM.

Wrench, J. S., \& Punyanunt, N. M. (2004). Advisee-advisor communication: An exploratory study examining interpersonal communication variables in the graduate advisee-advisor relationship. Communication Quarterly, 52(3), 224-236.

Zhai, L. (2004). Studying international students: Adjustment issues and social support. Journal of International Agricultural and Extension Education, 11(1), 97-104. 
Zhao, C., Golde, C. M. \& McKormick, A. C. 2007. More than a signature: How advisor choice and advisor behaviour affect doctoral student satisfaction. Journal of Further and Higher Education, 31(3), 263281 .

\section{Biographies}

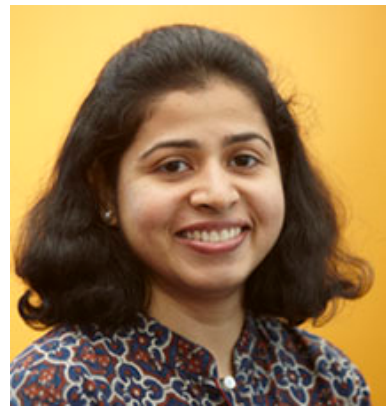

Simy Joy, Ph.D. is a lecturer in Organizational Behavior in Norwich Business School at University of East Anglia, UK. She received her $\mathrm{PhD}$ in Organizational Behavior from Case Western Reserve University, Cleveland, USA. Her research interests include emergent work and managerial practices (especially in non-Western parts of the world), diversity and inclusion, and internationalization of higher education. Before joining academia, she worked in the finance sector in the areas of training and development, organizational restructuring and change management.

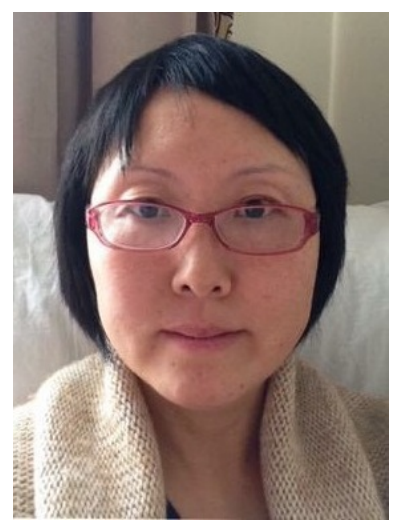

Xiangfen Liang holds a Ph.D. in Organizational Behavior from City University of Hong Kong. She has worked in the industry in marketing research and strategy consulting areas. Prior to her career in the industry, she worked at Case Western Reserve University, Cleveland, USA as a research staff member. She is a co-author of Gender Equity in Science and Engineering: Advancing Change in Higher Education (2012). She has published several articles in the areas of employee turnover behaviors, gender diversity and organizational transformation.

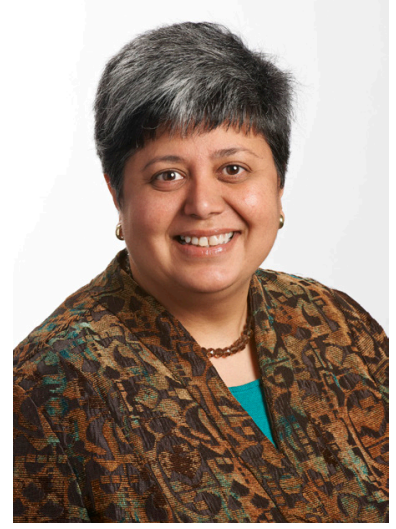

Diana Bilimoria, Ph.D. is KeyBank Professor and Chair and Professor of Organizational Behavior at the Weatherhead School of Management, Case Western Reserve University. She is a co-author of Women in STEM Careers: International Perspectives on Increasing Workforce Participation, Advancement and Leadership (2014), Gender Equity in Science and Engineering: Advancing Change in Higher Education (2012), Women on Corporate Boards of Directors: International Research and Practice (2009), and Handbook on Women in Business and Management (2007). She has published extensively in leading journals, and has contributed to several edited volumes. She has received grants from the National Science Foundation to advance women faculty in science and engineering. She served as the Chair of the Gender and Diversity in Organizations Division of the Academy of Management, was the editor of the Journal of Management Education, and serves on the editorial boards of several journals in the business and management field. Recent awards she received include the Weatherhead School of Management Teaching Excellence Award in 2014 and the Excellence in Higher Education Leadership Award from the ACE Ohio Women's Network in 2012. 


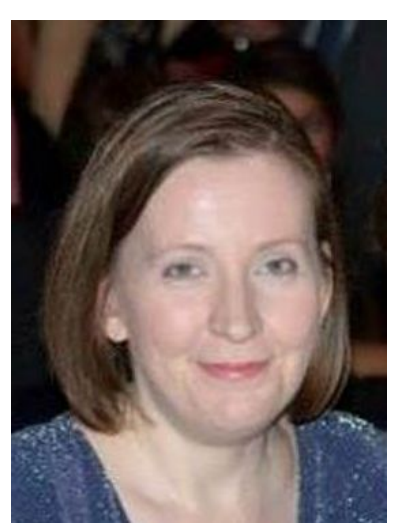

Susan R. Perry, Ph. D. is the University Director of Outcome Assessment at Case Western Reserve University. She received her Ph.D. in Experimental Psychology from the University of Tennessee, with a research focus on the drivers of academic success. In her current role, she leads the implementation of educational outcome assessment across the university. In prior work at CWRU, she served as a Senior Research Associate for the Academic Careers in Engineering and Science (ACES) program. 